\title{
RANCANG BANGUN PENJEJAK MATAHARI 2 SUMBU MENGGUNAKAN DATA RTC ( Real Time Clock ) UNTUK PANEL SURYA
}

\author{
Goro Sutarso Putra', Wakhyu Dwiono \\ Program Studi S1 Teknik Elektro, Universitas Muhammadiyah Purwokerto \\ Fakultas Teknik dan Sains, Universitas Muhammadiyah Purwokerto
}

\section{Informasi Makalah}

Dikirim, 13 Januari 2020

Direvisi, 16 Oktober 2020

Diterima, 16 Oktober 2020

\section{Kata Kunci:}

energi terbarukan, panel surya, penjejak matahari.

\section{Keyword:}

renewable energy, solar panels, solar tracking.

\begin{abstract}
INTISARI
Energi terbarukan adalah energi yang dapat diperbaharui dan tidak akan habis dalam waktu yang lama, energi terbarukan yang dapat dimanfaatkan untuk pembangkit listrik salah satunya adalah energi cahaya matahari sebagai energi alternatif dan memiliki potensi yang cukup tinggi karena ramah lingkungan. Pemanfaatan energi matahari menggunakan panel surya untuk mengubah energi cahaya matahari menjadi energi listrik. Daya dari keluaran panel surya masih kurang dioptimalkan sehingga perlu solusi dengan membuat sistem penjejak matahari dua sumbu atau empat arah yang mengikuti matahari berdasarkan rotasi bumi setiap hari dan gerak semu matahari tiap tahunnya dengan menggunakan metode pewaktu dari RTC(Real Time Clock) sebagai pengatur kemiringan panel surya dan penambahan sensor kecepatan angin untuk menghindari kerusakan saat terjadi angin kencang, sehingga pembuatan sistem penjejak matahari diharapkan menjadi solusi pengoptimalan daya keluaran panel surya dan sensor kecepatan angin sebagai pengaman dari sistem penjejak. Pada sistem penjejak matahari dua sumbu atau empat arah daya keluaran panel surya dibandingkan dengan daya keluaran panel surya statis dan panel surya berpenjejak matahari mengalami peningkatan dengan persentase peningkatan pada tanggal 27 November 2019 sebesar 40,04\% dan 28 November 2019 sebesar 75,85\% dengan rata-rata selisih kemiringan panel surya berdasarkan metode yang digunakan sebesar kurang lebih $2^{\circ}-3^{\circ}$ dengan batas kecepatan angin yang dibuat tidak lebih dari $2 \mathrm{~m} / \mathrm{s}$.
\end{abstract}

\begin{abstract}
Renewable energy is the energy collected from renewable resources and will not run out for a long time. It can be utilized for electricity generation, one of which is solar energy as alternative energy and has high potential because it is environmentally friendly. The utilization of solar energy uses solar panels to convert sunlight energy into electrical energy. The power from the solar panel output is still least optimized, so a solution is needed to make a two-axis or four-way solar tracking system. The system has to follow the sun position based on the earth's rotation every day. The motion of the sun each year can be determined using the RTC (Real Time Clock). The manufacture of solar tracking systems is expected to be a solution to optimize the output power of solar panels while the addition of wind speed sensors avoids damage in the event of strong winds when the panel tilt. In the two-axis or four-way solar tracking system, the output power of solar panels compared to the output power of static solar panels and solar panels has increased with the percentage increase on 27 November 2019 by 40.04\% and 28 November 2019 by $75.85 \%$ with the average difference in the slope of the solar panel based on the method used is approximately $2^{\circ}-3^{\circ}$ with a wind speed limit made no more than $2 \mathrm{~m} / \mathrm{s}$
\end{abstract}

Korespondensi Penulis: 
Goro Sutarso Putra

Program Studi Teknik Elektro

Fakultas Teknik dan Sains, Universitas Muhammadiyah Purwokerto

J1. Raya Dukuh Waluh Purwokerto, 53182.

Email: goro.sutarso@gmail.com

\section{PENDAHULUAN}

Energi terbarukan adalah suatu energi yang selalu terbaharui dan tidak akan habis dalam waktu yang cukup lama, macam-macam energi terbarukan yang dapat dimanfaatkan untuk pembangkit listrik contohnya adalah energi cahaya matahari[1][2]. Pembangkit Listrik Tenaga Surya(PLTS) adalah pembangkit listrik yang memanfaatkan energi matahari sebagai sumber energi pembangkitannya dengan menggunakan bantuan modul panel surya, Indonesia memiliki intensitas radiasi matahari yang cukup baik sehingga berpotensi untuk membangkitkan energi listrik sebagai sumber energi alternatif [3]. Intensitas cahaya matahari dipengaruhi oleh perubahan siang dan malam yang disebut rotasi bumi dan dipengaruhi oleh gerak semu tahunan matahari yang mengakibatkan matahari bergerak dari garis khatulistiwa bolak-balik antara $23,5^{\circ}$ Lintang Utara dan $23,5^{\circ}$ Lintang Selatan setiap tahun, sehingga agar panel surya tetap mengeluarkan daya optimal perlu adanya penjejak atau pengikut posisi matahari agar panel surya tetap dalam paparan sinar matahari[4][5]. Penjejak matahari di lingkungan bebas dapat terkena hempasan angin dari perubahan cuaca yang tidak dapat diprediksi, angin dapat menyebabkan kerusakan pada suatu pembangkit listrik tenaga matahari diakibatkan karena tingginya kecepatan angin[6].

Sistem penjejak matahari pernah diwujudkan dalam penelitian menggunakan sensor LDR, mikrokontroller Atmega8535 dan menggunakan dua buah motor stepper untuk mengarahkan panel surya menghadap kearah matahari dan panel surya yang digunakan berdimensi $7 \mathrm{~cm}$ x $5,5 \mathrm{~cm}$ dengan kenaikan tegangan sel surya mencapai 11,53\%[7], kemudian jenis penelitian yang sama menggunakan sensor LDR, mikrokontroller Arduino Uno dan menggunakan dua buah motor agar menghadap matahari dan panel surya yang digunakan adalah tipe polycristaline $50 \mathrm{Watt}[8]$, kemudian dengan sistem sama dan metode yang berbeda dalam [9] menggunakan solar radiation sensor dan panel surya 200 Watt mengalami peningkatan energi sebanyak $5,95 \%$ dan $9,87 \%$.

Berdasarkan latar belakang dan hasil penelitian di atas dibuat alat "Rancang Bangun Penjejak Matahari 2 Sumbu Menggunakan Data RTC (Real Time Clock) untuk Panel Surya” yang dilengkapi sensor angin untuk menghindari hempasan angin kencang dan sebagai pengaman sistem penjejak matahari dengan penggerak yang digunakan adalah linear aktuator 2 buah untuk dua sumbu dan penjejak matahari berdasarkan waktu dari data RTC (Real Time Clock) yang tidak terpengaruh cuaca mendung dan memiliki tingkat efisien yang lebih baik dalam menggerakan panel surya. Penelitian ini dibuat bertujuan untuk mengetahui seberapa besar hasil perbandingan antara panel surya berpenjejak dengan panel surya statis pada wilayah Purwokerto dengan memperhatikan posisi garis Lintang dan membuat proteksi pada panel surya terhadap kecepatan angin yang tinggi.

Techno Vol. 21, No. 2, Oktober 2020: $91-98$ 


\section{METODE}

\subsection{Diagram Flowchart Sistem}

Penjejak matahari empat arah atau dua sumbu kebebasan berdasarkan waktu menggunakan modul Real Time Clock (RTC) yang mengacu pergerakan rotasi dan revolusi bumi. Penjejak matahari ini dibuat dengan mengikuti arah matahari dari pukul 7 pagi sampai pukul 5 sore dengan sudut kemiringan panel yang disesuaikan dan mengikuti arah matahari berdasarkan gerak semu tahunan matahari tiap pekan dari $23,5^{\circ}$ Lintang Utara dan 23,5 Lintang Selatan. Gambar 1, memperlihatkan diagram alir dari urut-urutan langkah jalannya sistem penjejak matahari.

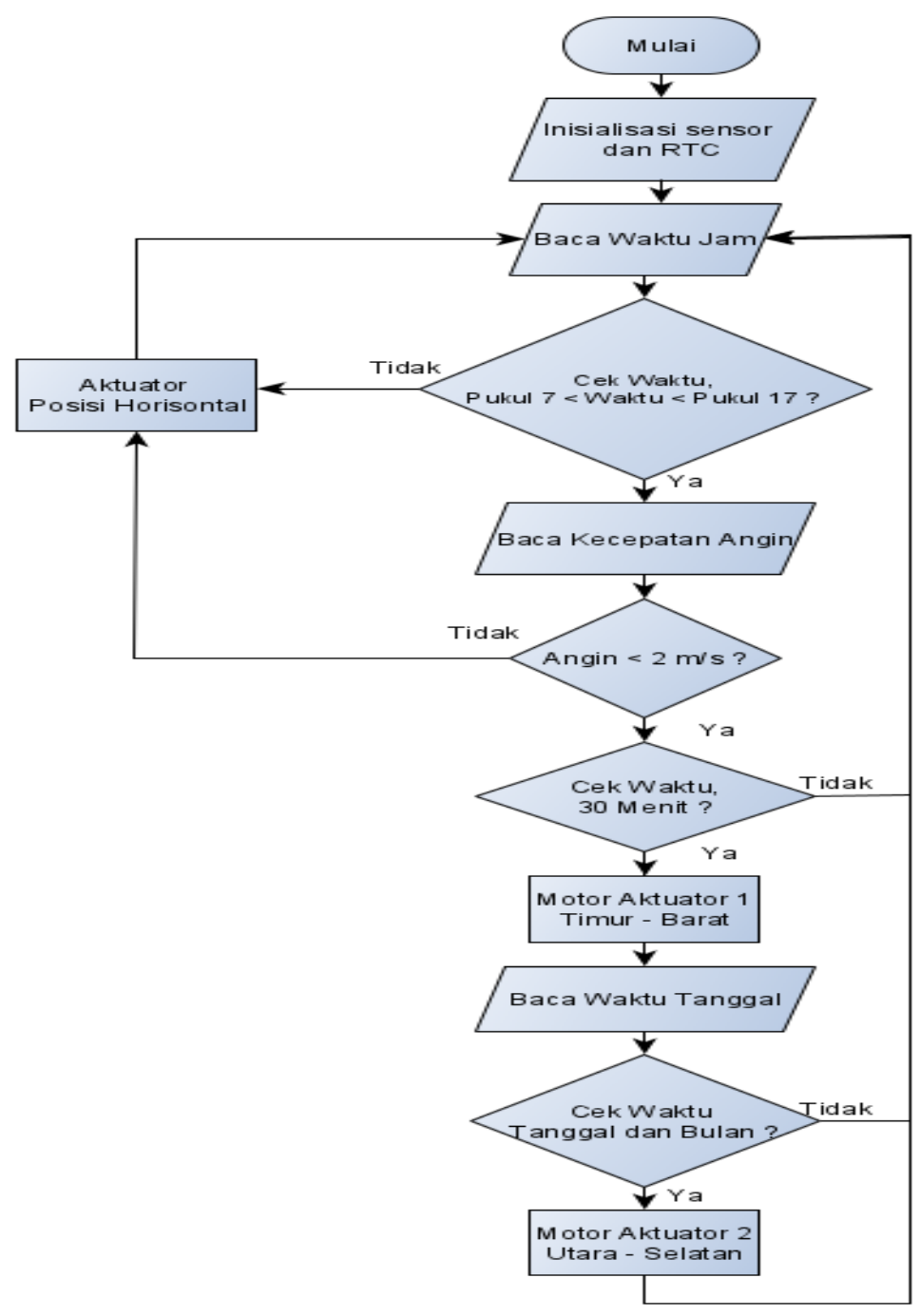

Gambar 1. Diagram Flowchart Sistem 


\subsection{Perancanngan Perangkat Keras}

Rangka panel surya berfungsi untuk menopang panel surya sehingga dapat terus mengikuti matahari berdasarkan waktu yang ditentukan. Rangka ini memiliki tinggi penyangga $100 \mathrm{~cm}$ dengan lebar $75 \mathrm{~cm}$ serta panjang bentangan dudukan panel surya sekitar $100 \mathrm{~cm}$. Desain rangka ini diperlihatkan dalam Gambar 2.

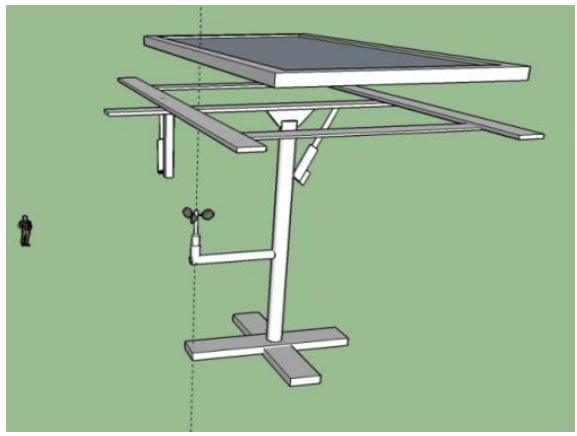

Gambar 2. Desain Rangka Panel Surya

\subsection{Pengujian Sistem Penjejak Matahari}

Pengambilan data dilakukan dengan cara pengukuran tegangan dan arus keluaran panel surya yang dibebani dengan lampu $100 \mathrm{~W}$ setiap 30 menit sehingga dapat diketahui berapa daya yang dihasilkan, pengukuran seperti Gambar 3 berikut.

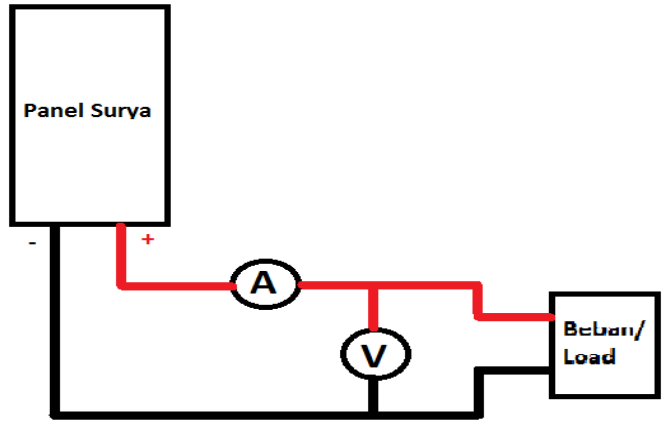

Gambar 3. Skema Pengujian Panel Surya

Setelah dilakukan pengukuran tiap 30 menit dari jam 07.00 - 17.00 dihasilkan tegangan dan arus panel surya, untuk mencari nilai daya yang dihasilkan dengan persamaan berikut.

Daya $(\mathrm{P})=$ Tegangan $(\mathrm{V}) \times$ Arus $(\mathrm{A})$

Untuk mengetahui tingkat efisiensi penjejak matahari dengan cara membandingkan nilai keluaran daya panel surya dengan keluaran daya panel surya statis, untuk mencari berapa persentase kenaikan daya yang di hasilkan seperti menggunakan persamaan berikut.

Persentase Daya $=\frac{(\text { Rata }- \text { Rata Daya Penjejak })-(\text { Rata }- \text { Rata daya Statis })}{\text { Rata }- \text { rata daya Statis }} \times 100 \%$ 


\section{HASIL DAN PEMBAHASAN}

Sistem penjejak matahari 2 sumbu menggunakan waktu RTC(Real Time Clock) untuk panel surya yang telah direalisasikan, diperlihatkan pada Gambar 4 dan 5 berikut.

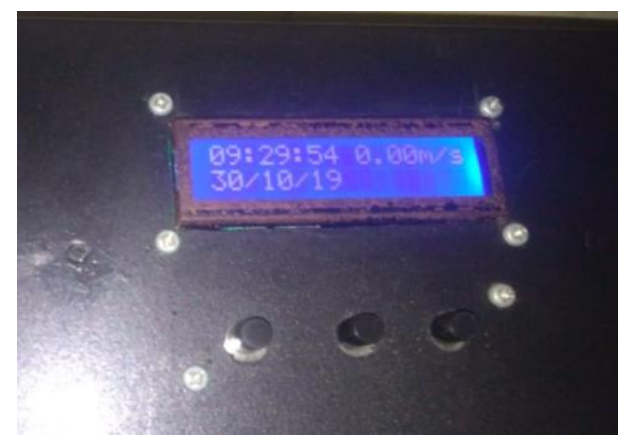

(Tombol Set) (Tombol Tambah) (TombolKurang )

Gambar 4. Sistem Kontrol Penjejak

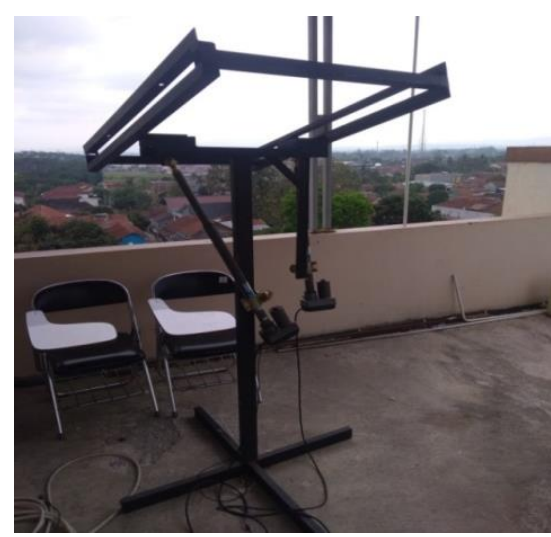

Gambar 5. Rangka Penjejak Matahari

\subsection{Pengujian Penjejak Matahari}

Pengujian dilakukan di atap atau rooftop gedung J Fakultas Psikologi, Universitas Muhammadiyah Purwokerto yang bertujuan agar saat pengujian panel surya tetap mendapat sinar matahari dari pagi hari sampai sore hari, lokasi atap juga dipilih karena tidak terhalang oleh bangunan atau pohon karena posisi gedung yang cukup tinggi sehingga tidak menghalangi cahaya matahari ke panel surya. Proses pengujian panel surya dengan penjejak matahari dan panel surya statis diperlihatkan pada Gambar 6 berikut.
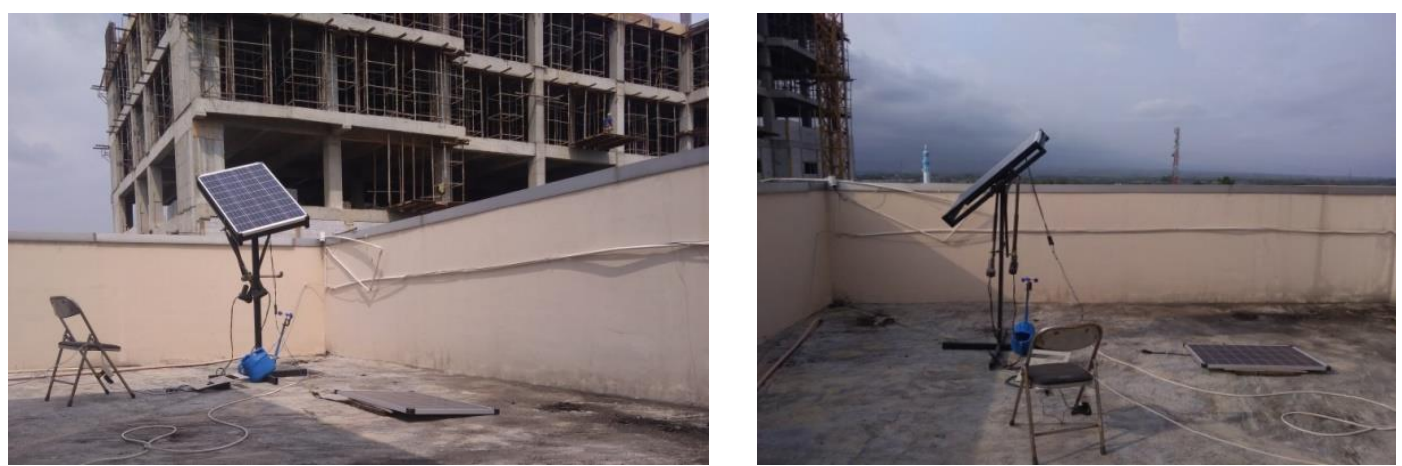

Gambar 6. Pengujian pada pukul 08.00 (kiri) dan pukul 15.00 (kanan) 
Panel surya dibebani dengan beban sebesar 100 watt yang berupa lampu, kemudian arus dan tegangan panel surya diukur. Daya dihitung berdasarkan Persamaan 1. Sebagai pembanding, adalah data pengukuran pada panel surya yang tidak diubah-ubah kemiringannya, dan dengan pembebanan yang sama. Perbandingan daya antara panel surya yang statis dengan yang diatur menggunakan penjejak matahari, dihitung menggunakan Persamaan 2.

8.

Data hasil pengujian tersebut disajikan dalam bentuk grafik seperti diperlihatkan pada Gambar 7 dan

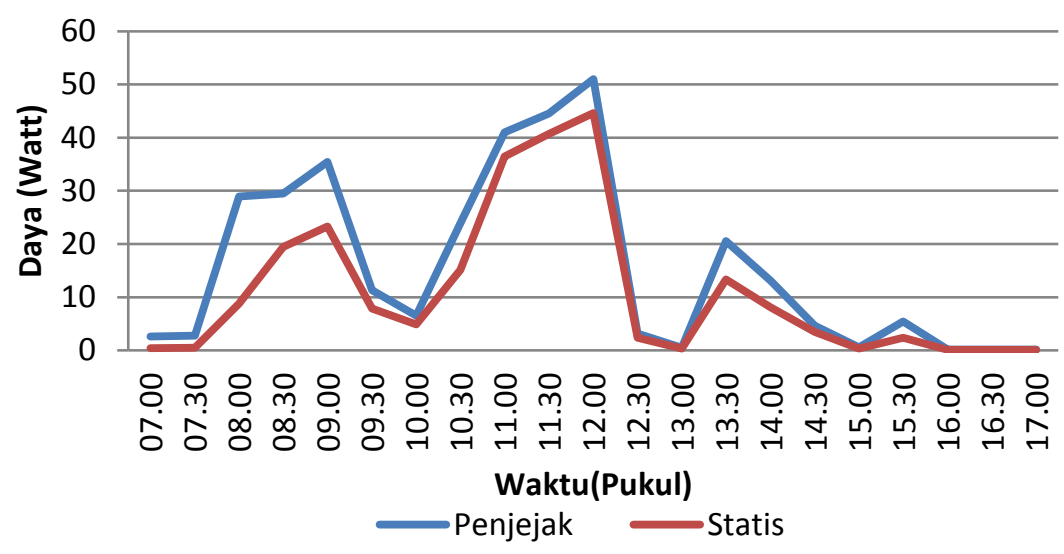

Gambar 7. Grafik Pengukuran Keluaran Panel Surya Tanggal 27 November 2019

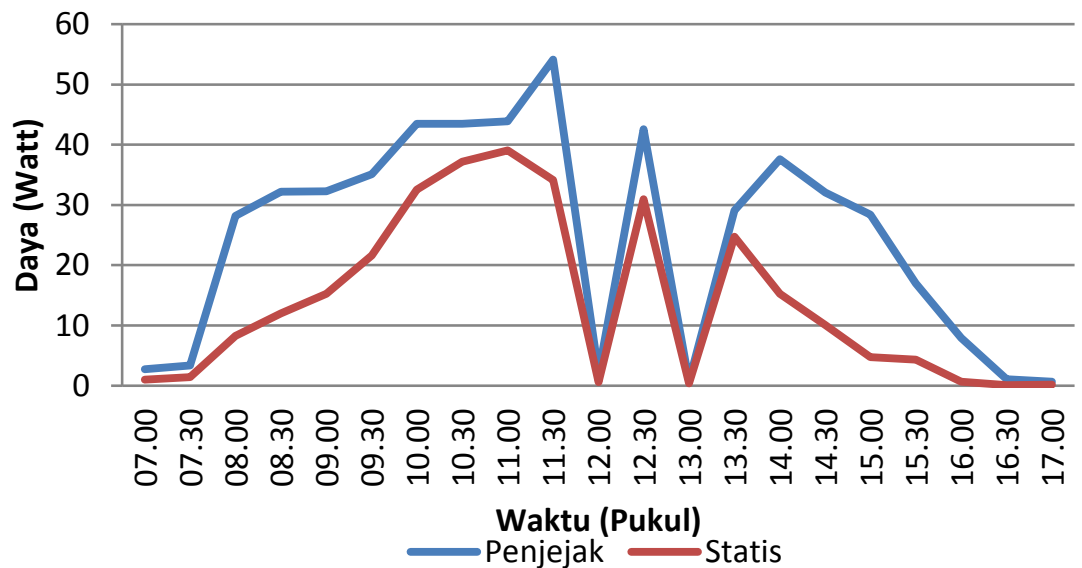

Gambar 8. Grafik Pengukuran Keluaran Panel Surya Tanggal 28 November 2019

Berdasarkan pada grafik yang diperlihatkan dalam Gambar 7 dan Gambar 8 di atas dapat dilihat bahwa nilai daya paling tinggi pada tanggal 27 November 2019 yaitu pukul 12.00 dengan nilai daya keluaran panel surya berpenjejak adalah 51,016 Watt dan daya keluaran pada panel surya statis adalah 44,632 Watt. Nilai ratarata daya untuk panel surya berpenjejak dari pagi hari sampai sore hari adalah 15,52 Watt dan rata-rata untuk panel surya statis adalah 11,08 Watt. Pada tanggal 28 November yaitu pukul 11.30 dengan nilai daya keluaran panel surya berpenjejak adalah 54,12 Watt dan daya keluaran pada panel surya statis pada pukul 11.00 adalah 39,052 Watt dan nilai rata-rata daya untuk panel surya berpenjejak dari pagi hari sampai sore hari adalah 24,66 Watt dan rata-rata untuk panel surya statis adalah 14,02 Watt. Perbandingan daya dari panel surya berpenjejak matahari dengan panel surya statis pada tanggal 27 November 2019 mengalami peningkatan pada panel surya berpenjejak sebesar 40,04 \% dan tanggal 28 November 2019 sebesar 75,85\%, daya keluaran didapatkan nilai yang tidak stabil karena dipengaruhi oleh keadaan cuaca pada saat pengujian sehingga mempengaruhi cahaya matahari ke panel surya. 


\subsection{Pengujian Sensor Kecepatan Angin}

Pengujian kecepatan angin dilakukan bersamaan dengan mengukur daya keluaran panel surya setiap 30 menit dan diperoleh data pengukuran seperti Gambar 9 berikut.

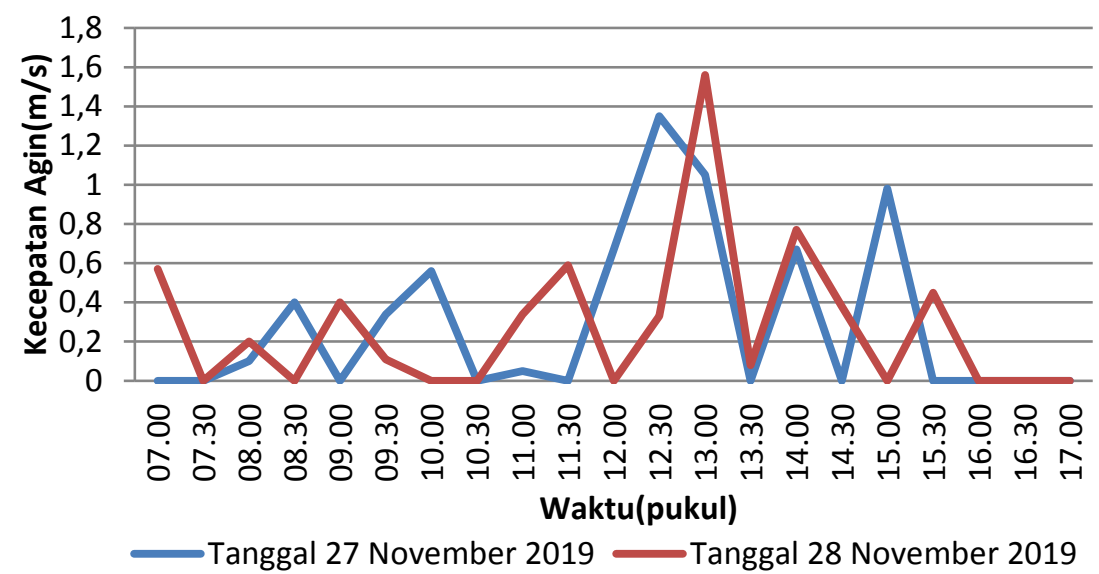

\section{Gambar 9. Grafik Pengujian Sensor Kecepatan Angin}

Berdasarkan pada grafik data kecepatan angin tersebut, terlihat bahwa kecepatan angin bernilai antara $0 \mathrm{~m} / \mathrm{s}$ hingga $1.6 \mathrm{~m} / \mathrm{s}$. Kecepatan $0 \mathrm{~m} / \mathrm{s}$ dapat diartikan bahwa pada saat pengukuran tidak ada angin meskipun sebenarnya dapat dirasakan adanya hembusan angina yang perlahan. Hal ini dikarenakan sensor angin tidak bisa berputar pada kecepatan yang rendah, sehingga kondisi ini disebut sebagai Dead Zone atau zona. Sensor angin yang diterapkan dalam sistem penjejak matahari ini merupakan pengaman dari kecepatan angin kencang. Sistem pengaman ini berfungsi dengan baik ketika disimulasikan menggunakan angin berkecapatan lebih dari $2 \mathrm{~m} / \mathrm{s}$ maka posisi panel surya berubah kemiringan menjadi posisi horizontal untuk mengurangi daya dorong angin.

\section{KESIMPULAN}

Dari hasil penelitian yang telah dilakukan dapat disimpulkan bahwa sistem penjejak matahari 2 sumbu menggunakan data RTC (Real Time Clock) untuk panel surya telah berhasil dibuat dan memiliki kinerja seperti yang diharapkan. Daya keluaran panel surya berpenjejak adalah lebih tinggi jika dibandingkan dengan panel surya statis. Sistem proteksi kecepatan angin bekerja sesuai yang diharapkan yaitu dengan mengubah posisi panel surya menjadi horisontal saat kecepatan angin melebihi dari yang ditentukan atau melebihi $2 \mathrm{~m} / \mathrm{s}$.

\section{DAFTAR PUSTAKA}

[1] Lubis, A. Energi Terbarukan dalam Pembangunan Berkelanjutan, Jurnal Teknologi Lingkungan. Vol 8, No 2, hal:155-162, 2011.

[2] NN, International Energy Outlook 2019, U.S. Energy Information Administration Office of Energy Analysis, U.S. Department of Energy Washington, DC 20585, https://www.eia.gov/ieo

[3] Sahlan, Analisis Strategi Teknologi Plts Fotovoltaik Di Indonesia Terhadap Nilai Eqivalensi Dan Pemanfaatan Perwilayah, Jurnal Power Plant, Vol. 5, No. 1, 2017

[4] Mona Berlian Sari, Yulkifli, Zulhendri Kamus, Sistem Pengukuran Intensitas dan Durasi Penyinaran Matahari Realtime PC berbasis LDR dan Motor Stepper, Jurnal Otomasi Kontrol dan Instrumentasi, Vol 7, No 1, 2015.

[5] Ilyas, Ishak Kasim, Peningkatan Efisiensi Pembangkit Listrik Tenaga Surya Dengan Reflektor Parabola, Jetri : Jurnal Ilmiah Teknik Elektro, Vol.14, No 2, 2017.

[6] Emilya Nurjani, Arum Rahayu, Febriyan Rachmawati, Kajian Bencana Angin Ribut Di Indonesia Periode 1990-2011: Upaya Mitigasi Bencana, Geomedia Vol. 11 No.2, 2013

[7] Syafrialdi, R. Rancang Bangun Solar Tracker Berbasis Mikrokontroler Atmega8535 dengan Sensor LDR dan Penampil LCD. Jurnal Fisika Unand, Vol 4, No 2, 2015

[8] Basyir, A. A, Penjejak Sinar Matahari. Skripsi, Fakultas Teknik dan Sains Universitas Muhammadiyah Purwokerto, 2018.

[9] Robles Algarin, C. A., Ospino Castro, A. J., \& Naranjo Casas, J., Dual-axis Solar Tracker for Using in Photovoltaic Systems, International Journal of Renewable Energy Research-IJRER, Vol 7, No.1, 2017. 
